\title{
Spatial Analysis of Water Quality in Parts of Rivers Niger and Kaduna Catchments,
} North Central, Nigeria

\author{
IDRIS, Aliyu Ja'agi ${ }^{1 \star}$ \\ Yahaya, T. I. ${ }^{2}$ \\ Abubakar, A. S. ${ }^{3}$ (D) \\ Jigam, A. A. ${ }^{4}$
}

${ }_{1,2, s}$ Department of Geography, Federal University of Technology Minna, Niger State, Nigeria.

Email:alivuidrisjaagi@yahoo.comTel: +2348034576625

Email:ivandatayo@futminna.edu.ng.Tel:+23480359558ss

${ }^{3}$ Email: sadauki@futminna.edu.ng Tel:+2348034518108

'Department of Biochemistry, Federal University of Technology Minna, Niger State, Nigeria.

'Email:alijigam@yahoo.com Tel:+2348036136862

\begin{abstract}
It is understood that human activities have continue to alter the physico-chemical patterns of water and it's resources, which has resulted into poor water quality in the study area. As comprehensive distribution of water quality parameters in the study area is of great interest, there exist a golden opportunity to consider a study with GIS aided spatial coverage beyond laboratory analytical dimensions. Thus, a total of thirty two (32) samples of water and sediment were collected during rainy and dry season for physico-chemical analysis. Water samples collected were analysed in situ for seven (7) parameters using HANNA multiparameter analyser and eight (8) other parameters were analysed in the analytical laboratory following standard methods. The finding revealed a significant number of parameters analysed were beyond regulatory limits. It is hence recommended that visible policies aimed at ensuring good water quality in the study area are critical for sustainability.
\end{abstract}

Keywords: Physico-chemicals, Sediments, Water quality, Health, Environment, GIS, Rivers, Spatial Distribution.

Citation | IDRIS, Aliyu Ja'agi; Yahaya, T. I.; Abubakar, A. S.; Jigam, A. A. (2020). Spatial Analysis of Water Quality in Parts of Rivers Niger and Kaduna Catchments, North Central, Nigeria. Asian Review of Environmental and Earth Sciences, 7(1): 72-78. History:

Received: 7 July 2020

Revised: 10 August 2020

Accepted: 3 September 2020

Published: 24: September 2020

Licensed: This work is licensed under a Creative Commons Attribution 3.0 License (cc) E

Publisher: Asian Online Journal Publishing Group
Acknowledgement: All authors contributed to the conception and design of the study.

Funding: This study received no specific financial support.

Competing Interests: The authors declare that they have no conflict of interests.

Transparency: The authors confirm that the manuscript is an honest, accurate, and transparent account of the study was reported; that no vital features of the study have been omitted; and that any discrepancies from the study as planned have been explained.

Ethical: This study follows all ethical practices during writing.

\section{Contents}

1. Introduction

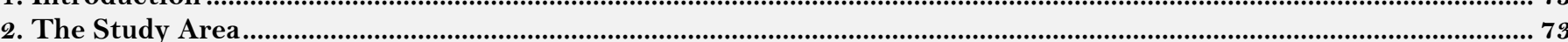

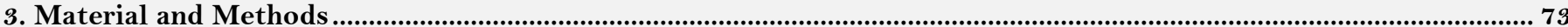

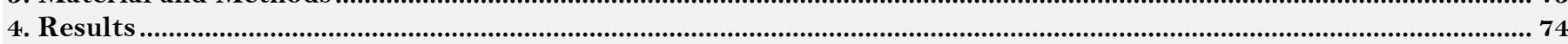

5. Conclusion

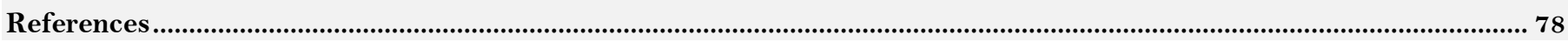




\section{Contribution of this paper to the literature}

This study has been able to demonstrate comprehensive GIS aided spatial distribution of physic chemical characteristics of water and sediment with regard to water quality assessment which non known related past studies have done in the study area.

\section{Introduction}

It is a common knowledge that human activities continue to elicit widespread effect on the physical, chemical and biological processes within aquatic ecosystems [1, 2]. Poor water quality in the study area can result into a serious threat to the existence of human and biodiversity at large. Rivers Niger and Kaduna catchments are characterised by arable land where majority of its people practice farming [3]. This practice can eventually cause degradation of water quality and disproportionate effect on the socio-economic wellbeing of the communities in the area.

Spatial analyses are any types of data analyses that extract and/or produce spatial information based on operations on different layers of data. GIS provides the organizational framework which allows numerical and statistical analyses to be easily applied on real-world data. The simple, but essential and fundamental ability to overlay a basically unlimited number of GIS layers together with hundreds of tools (GIS functions performing computations on spatial data) to be used for solving issues of spatial analysis and spatial statistics is what makes GIS so different from using hardcopy maps. Spatial analysis with GIS has been used in many studies to demonstrates the breadth of its utility in the field of environmental sciences [4].

Communities in the study area depend on these Rivers for livelihood [5] and lack of comprehensive research information about the physico-chemical status of the rivers informed the need for immediate investigation in the area. Also, as comprehensive distribution of water quality parameters in the study area is of great interest, there exist a golden opportunity to consider a study with spatial coverage beyond laboratory analytical dimensions. Finding of this study will provide opportunity for researchers and relevant stakeholders to improve on future studies and overall environmental performance.

\section{The Study Area}

The study area for the investigation is communities in parts of Rivers Niger and Kaduna Catchment areas, Niger State which lies between Longitude $3^{\circ} 30^{\prime} \mathrm{N}$ and $7^{\circ} 20^{\prime} \mathrm{E}$ and Latitude $8^{\circ} 22^{\prime} \mathrm{N}$ and $11^{\circ} 30^{\prime} \mathrm{N}$; located at the Guinea Savanah vegetation zone in the north central part of Nigeria Figure 1 [5]. The study area was divided into zones according to agroecological factors. Along River Niger, the Upper zone is from Rabba village in Mokwa Local Government Area (LGA), Middle zone is at Muregi and the Lower zone is after Muregi in Mokwa LGA down to Baro village in Agaie LGA. Study area along River Kaduna was divided into two zones. Upper zone is from Wuya village in Lavun LGA and the Lower zone from half way down to Muregi. The major economic activities of the communities living around the area are agriculture and fishing. These are the leading sector in terms of employment, income earning and overall contribution to the socio-economic wellbeing of the people. The Kaduna and Niger River flood plains are many kilometers wide at the downstream of Nupe basement boundary, two major streams Yanko ikko, Dumi, Ebigi. All these empty their waters in to Niger River [5].

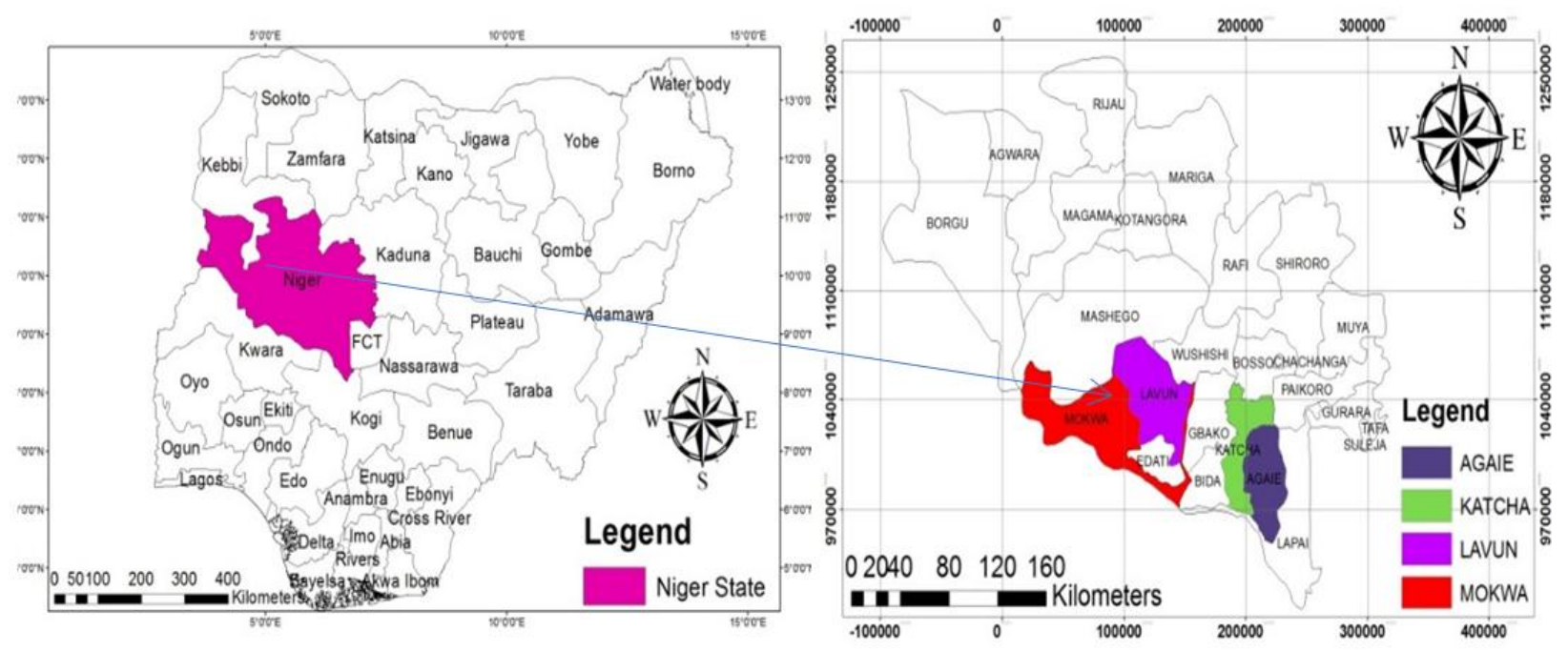

Figure-1. Map of the study area showing parts of Rivers Niger and Kaduna Catchment, North Central, Nigeria.

\section{Material and Methods}

(a) Sampling Point's Identification

Water samples were collected from eight selected sampling points in the study area Figure 2. The eight sampling points were based on altitude and information from the key stakeholders in the area. Samples were collected using standard procedures for water sample collection and preservation. Each sampling point were georeferenced using Global Position System (GPS) device in longitude and latitude in Degree, Minutes and Seconds (DMS) format. 


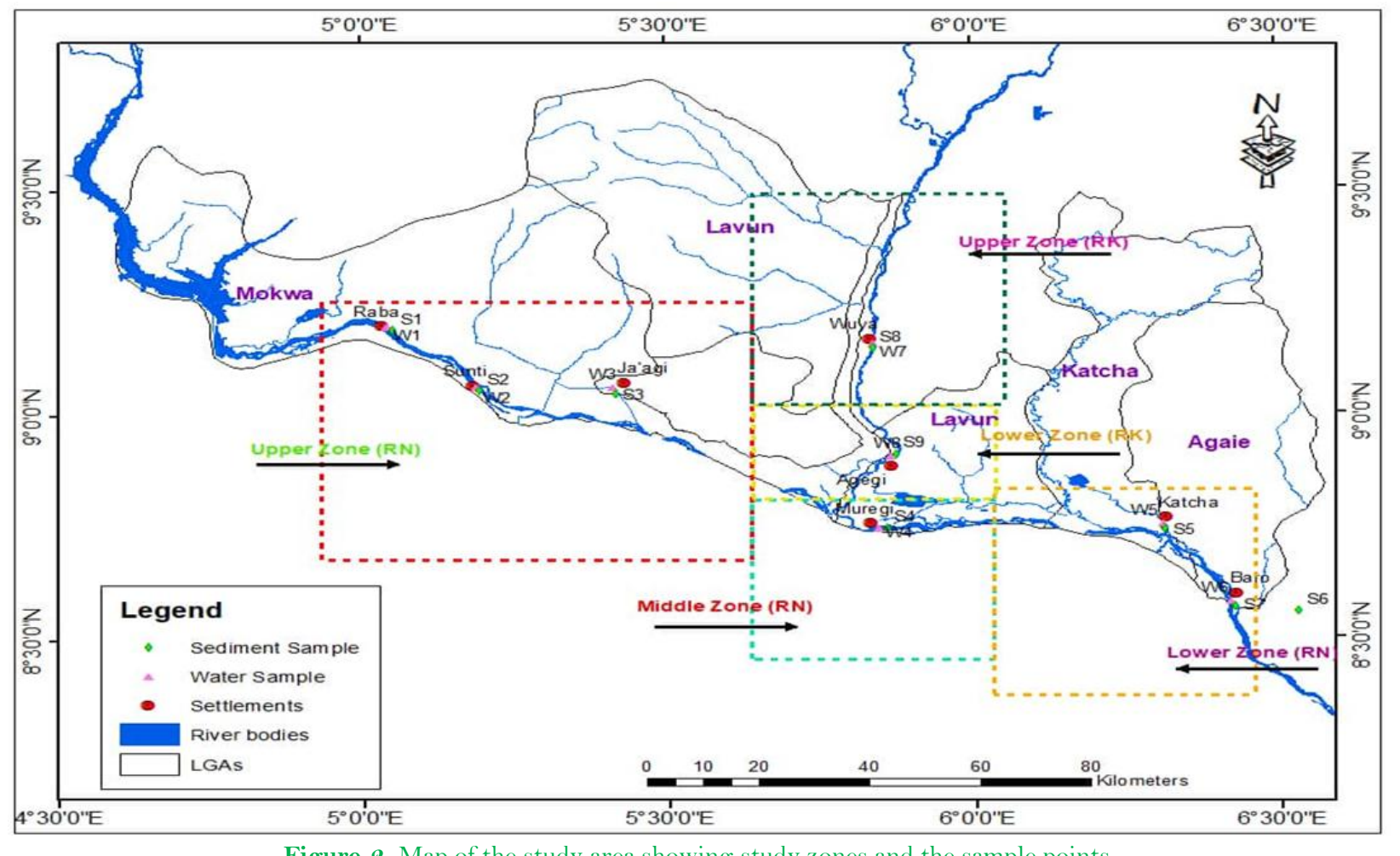

Figure-2. Map of the study area showing study zones and the sample points.

\section{(b) Water Sampling and Preservation}

A total of thirty two (32) samples of water and sediment were collected during rainy and dry season for physico-chemical analysis. Water samples collected were analysed in situ for seven (7) parameters using HANNA multiparameter analyser. The samples were preserved in ice flasks and transported immediately to the reference laboratory. Upon arrival, water and sediment samples were extracted and analysed immediately for eight (8) other parameters following the method outlined by Federation \& American Public Health Association FAPHA [6].

\section{(c) Spatial Data Analysis}

The GPS location data earlier captured from the all sample points and the values for the physico-chemical parameters obtained from analytical processes were transferred into Excel package of the Microsoft Office software, sorted and saved in Tab delimited file format that is compactible in ArcGIS environment.

ArcMap was lunched and the prepared dataset was imported into the table of content in the GIS interface using the tab delimited as file format, Universal Transverse Mercator (UTM) Projection system was chosen and set to Zone $32 \mathrm{~N}$. Therefore, Interpolation was done using the spatial analysis extension toolbox of the ArcGIS (version 10.5), the Inverse Distance Weighted (IDW) technique was chosen because it uses the measured values surrounding the prediction location to predict a value for any unsampled location, based on the assumption that things that are close to one another are more alike than those that are further apart.

Finally, at the tab of IDW interface, the sample points were selected separately and imported, the output was saved and then OK for processing. The result maps were then exported in JPEG format after adding neat-line, grid, north arrow, scale and legend for presentation and discussion.

\section{Results}

\subsection{Spatial Distribution of Physico-Chemical Characteristics of Water Samples during Rainy Season}

As revealed in Figure 3, the value of $\mathrm{pH}$ ranges between 5.2 and 7.4, Salinity ranges between 41PSU and 81PSU, Temperature ranges between $22.1^{\circ} \mathrm{C}$ and $23.3^{\circ} \mathrm{C}$, Dissolved oxygen (DO) ranges between $6.9 \mathrm{mg} / 1$ and $8.6 \mathrm{mg} / \mathrm{l}$, Conductivity ranges between $16 \mu \mathrm{s} / \mathrm{cm}$ and $43 \mu \mathrm{s} / \mathrm{cm}$, Total Dissolved Solids (TDS) value ranges between $17.8 \mathrm{ppm}$ and $23.6 \mathrm{mg} / \mathrm{l}$, Turbidity ranges between $47 \mathrm{NTU}$ and $96 \mathrm{NTU}$, Sulphate concentrations ranges between $0.72 \mathrm{ppm}$ and $1.95 \mathrm{ppm}$, Manganese $(\mathrm{Mn})$ ranges between $0.15 \mathrm{ppm}$ and $0.98 \mathrm{ppm}$, Chloride concentrations ranges between 18.51ppm and 78.79ppm. Chemical Oxygen Demand (COD) ranges between 13.8ppm and 23.85ppm, Biochemical Oxygen Demand (BOD) ranges between $7.05 \mathrm{ppm}$ and $12.56 \mathrm{ppm}$, Total Suspended Solid (TSS) ranges between $15.81 \mathrm{ppm}$ and $38.87 \mathrm{ppm}$, Total Hardness $(\mathrm{TH})$ ranges between 3.32ppm and $7.65 \mathrm{ppm}$ and Potassium ranges between $0.08 \mathrm{ppm}$ and $1.54 \mathrm{ppm}$ across the study area during rainy season.

The $\mathrm{pH}$, salinity, temperature, DO, sulphate, chloride, TH and potassium values obtained are all within Nigeria regulatory limit. The values of TDS, turbidity, Mn, COD, BOD, TSS in the study area are largely above Nigeria regulatory limits. The relatively high levels of a number of these parameters (which are largely higher than that of dry season) can be attributed to higher farming activities in rainy season, presence of decaying organic matter due to intense use of plant minerals and pesticides in the study area. These values are also indications of polluted water which are capable of increasing the concentrations of hazardous chemical (particularly from intense agrochemical use by farmers) in water in the study area. 


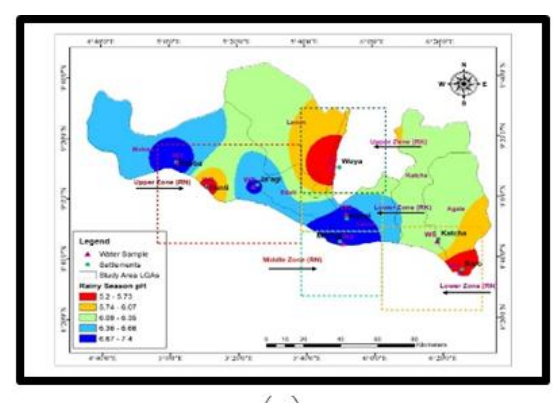

a)

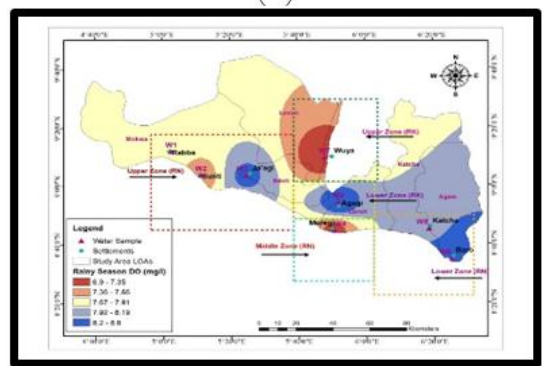

(d)

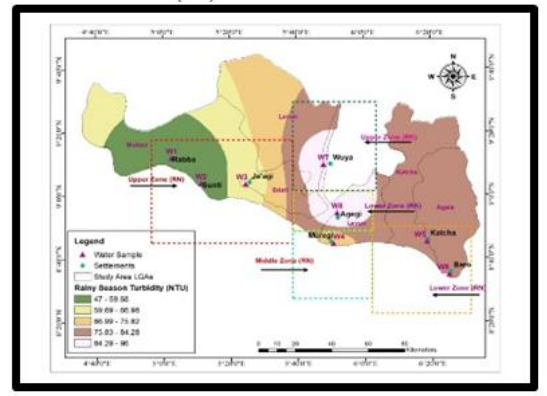

$(\mathrm{g})$

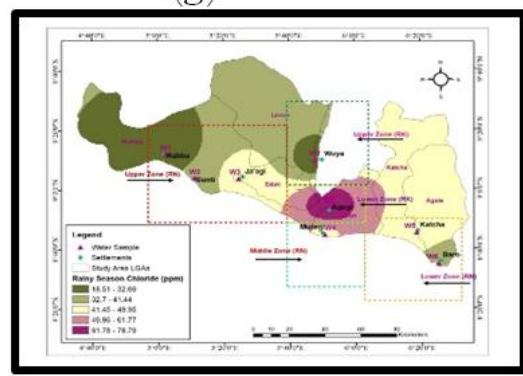

(j)

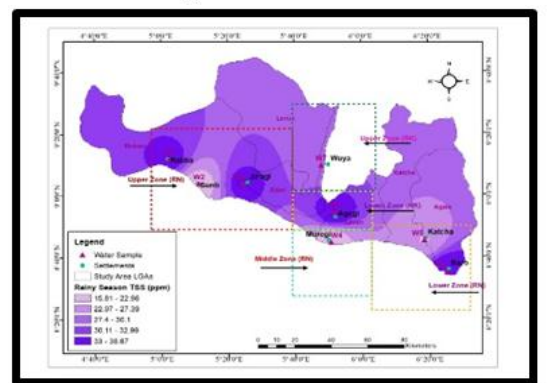

(m)

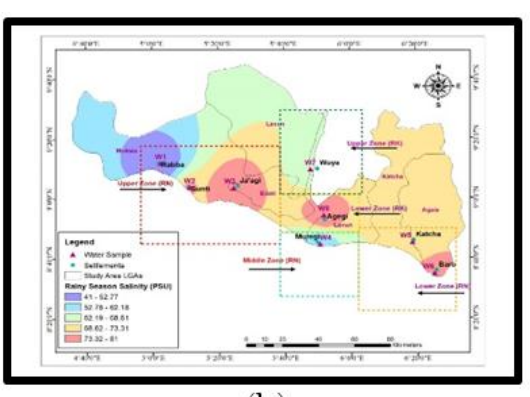

(b)

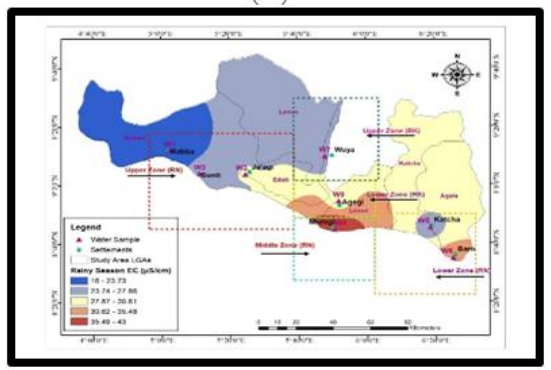

(e

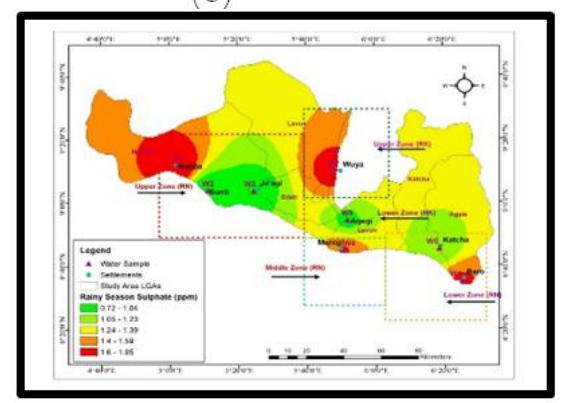

(h)

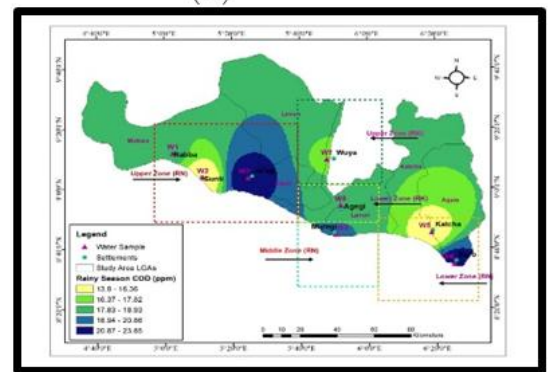

(k)

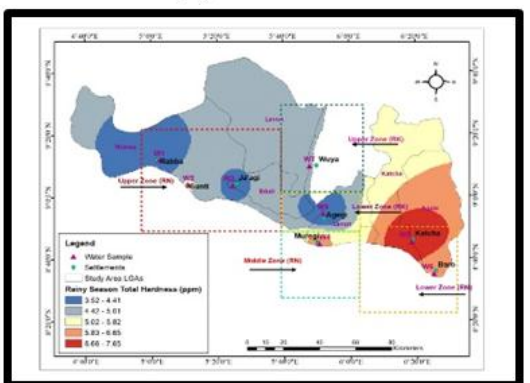

(n)
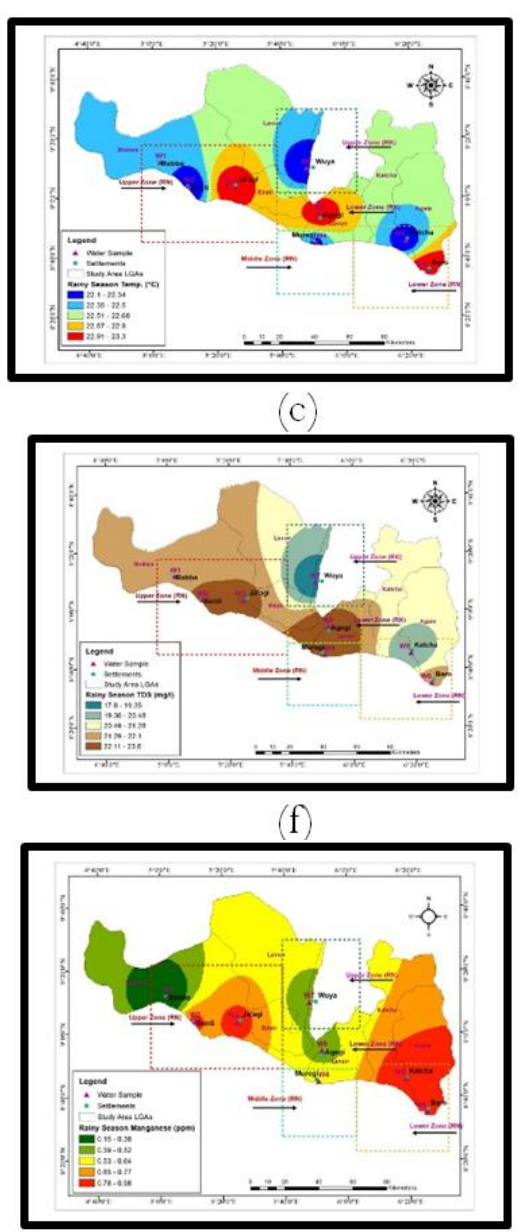

(i)

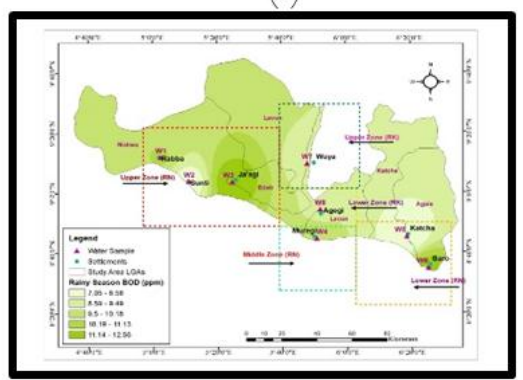

(1)

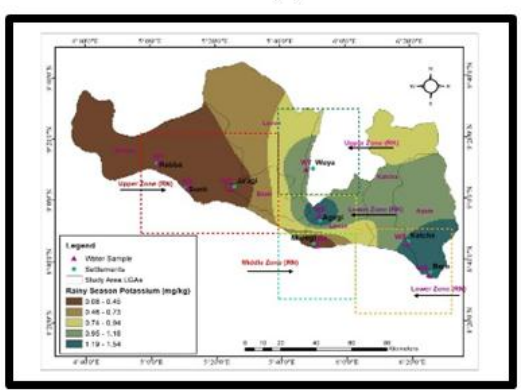

(O)

Figure-3. Interpolated Distance Weighted maps of (a) pH (b) Salinity, (c) Temperature, (d) DO, (e) Conductivity, (f) TDS, (g) Turbidity, (h) Sulphate, (i) Mn, (j) Chloride, (k) COD, (l) BOD, (m) TSS, (n) TH and (o) Potassium of water samples during rainy season.

\subsection{Spatial Distribution of Physico-Chemical Characteristics of Water Samples during Dry Season}

As revealed in Figure 4, the value of $\mathrm{pH}$ ranges between 5.4 and 6.9, Salinity ranges between 28PSU and 64PSU, Temperature ranges between $25.12^{\circ} \mathrm{C}$ and $28.1^{\circ} \mathrm{C}$, Dissolved oxygen (DO) ranges between $5.3 \mathrm{mg} / 1$ and $6.6 \mathrm{mg} / \mathrm{l}$, Conductivity ranges between $10 \mu \mathrm{s} / \mathrm{cm}$ and $30 \mu \mathrm{s} / \mathrm{cm}$, Total Dissolved Solids (TDS) value ranges between $6.7 \mathrm{ppm}$ and $20.1 \mathrm{mg} / \mathrm{l}$, Turbidity ranges between $12.71 \mathrm{NTU}$ and $88 \mathrm{NTU}$, Sulphate concentrations ranges between $0.69 \mathrm{ppm}$ and $2.15 \mathrm{ppm}$, Manganese $(\mathrm{Mn})$ ranges between $0.08 \mathrm{ppm}$ and 1.06ppm, Chloride concentrations ranges between $35.51 \mathrm{ppm}$ and 105.98ppm. Chemical Oxygen Demand (COD) ranges between 24.81ppm and 44.99ppm, Biochemical Oxygen Demand (BOD) ranges between 9.82ppm and 18.1ppm, Total Suspended Solid (TSS) ranges between 30ppm and 53ppm, Total Hardness $(\mathrm{TH})$ ranges between 4.6ppm and 10.52ppm and Potassium ranges between $0.13 \mathrm{ppm}$ and $2.07 \mathrm{ppm}$ across the study area.

The values of TDS, turbidity, Mn, COD, BOD, TSS in the study area are largely above Nigeria regulatory limits. The relatively high levels of a number of these parameters during dry season (although largely lower than that of rainy season) can also be attributed to the presence of decaying organic matter due to use of plant minerals and pesticides in the study area. These values are also indications of polluted water which are capable of increasing the concentrations of hazardous chemical (particularly from intense agrochemical use by farmers) in water in the study area. 


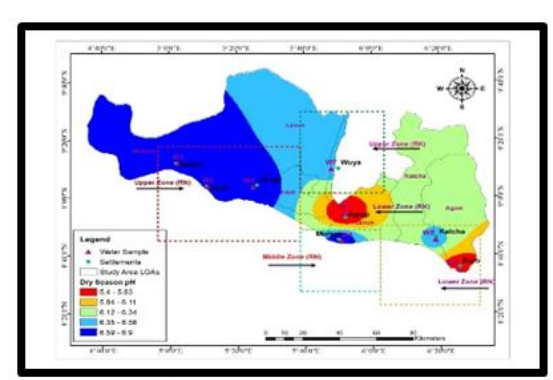

(a)

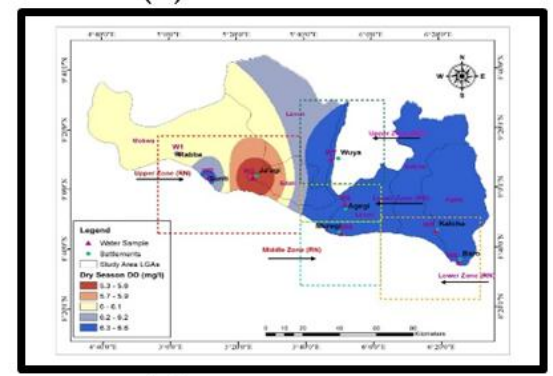

(d)

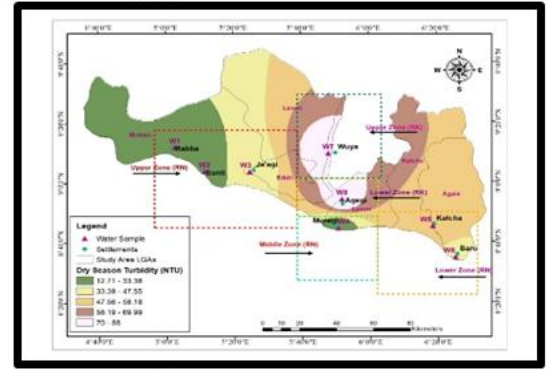

(g)

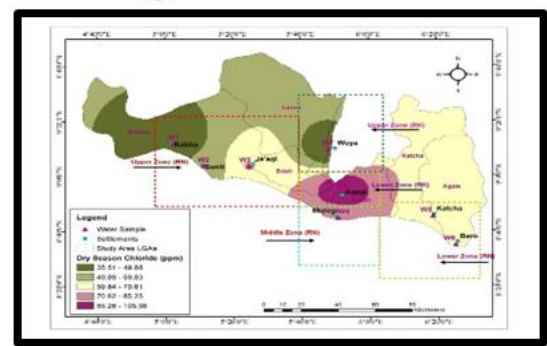

(j)

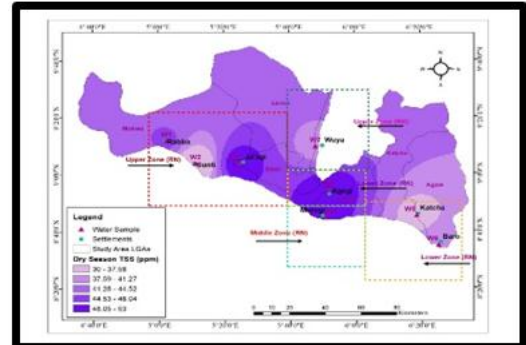

(m)

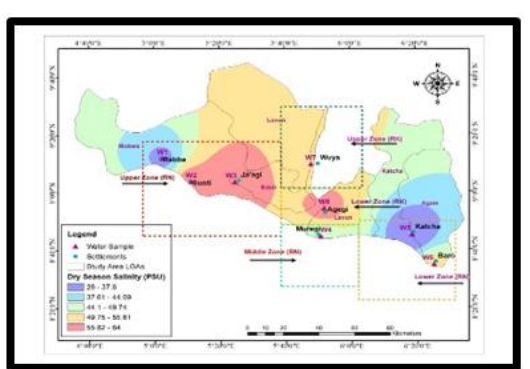

(b)

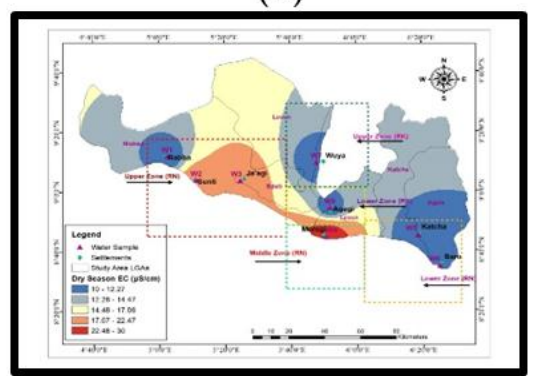

(e)

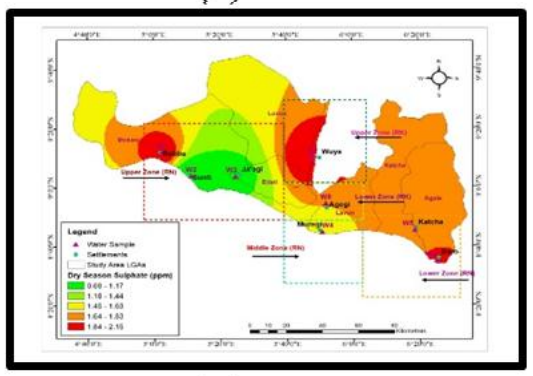

(h)

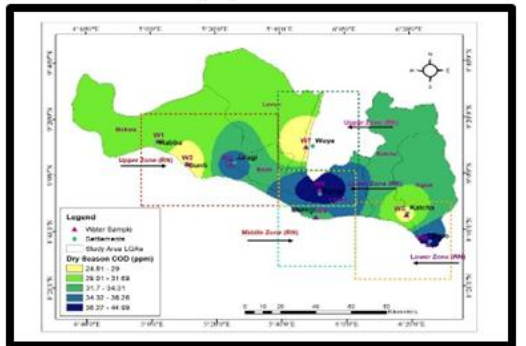

$(\mathbf{k})$

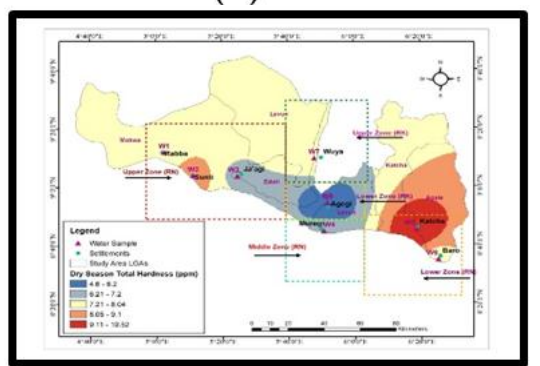

(n)

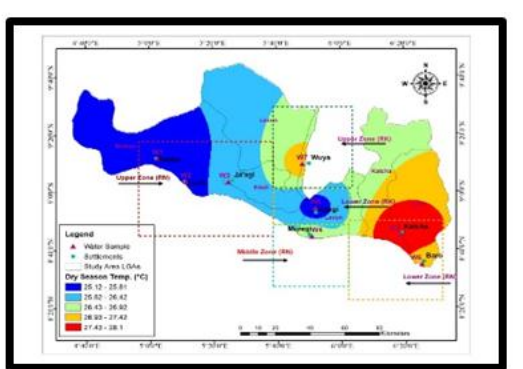

(c)

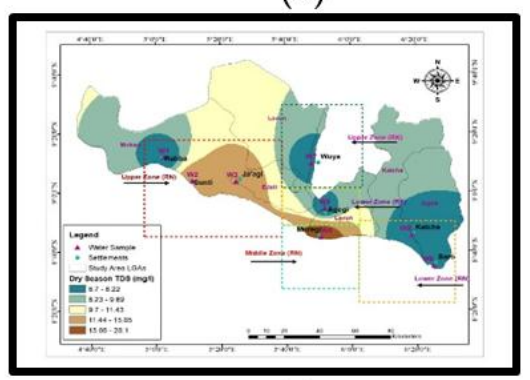

(f)

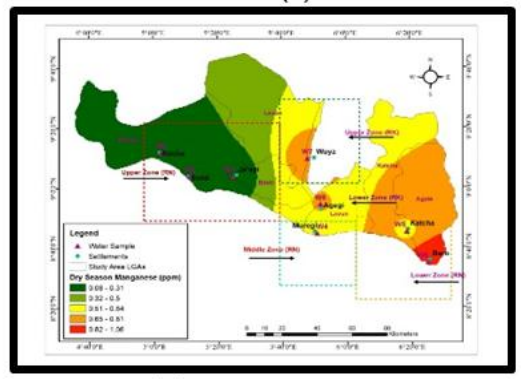

(i)

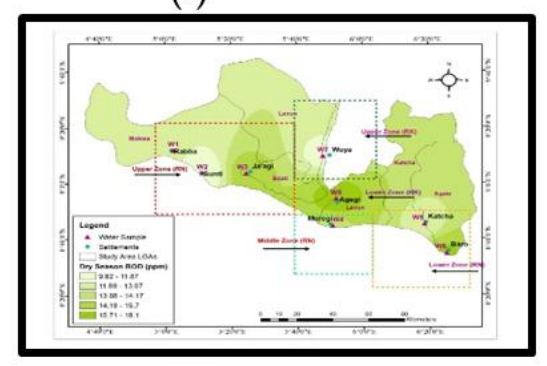

(1)

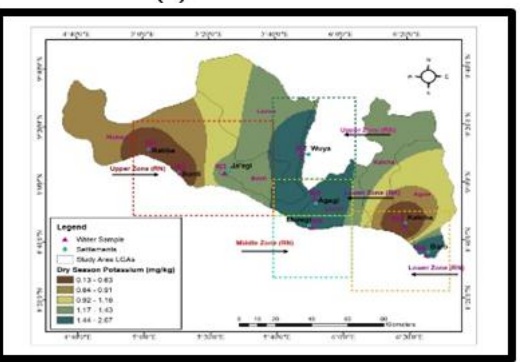

(o)

Figure-4. Interpolated Distance Weighted maps of (a) pH (b) Salinity, (c) Temperature, (d) DO, (e) Conductivity, (f) TDS, (g) Turbidity, (h) Sulphate, (i) Mn, (j) Chloride, (k) COD, (l) BOD, (m) TSS, (n) TH and (o) Potassium of water samples of dry season.

\subsection{Spatial Distribution of Physico-Chemical Characteristics of Sediment Samples during Rainy Season}

As revealed in Figure 5, the value of Sulphate concentrations ranges between 4.61ppm and 8.62ppm, Manganese $(\mathrm{Mn})$ ranges between $0.96 \mathrm{ppm}$ and $2.86 \mathrm{ppm}$, Chloride concentrations ranges between $5.13 \mathrm{ppm}$ and $32.65 \mathrm{ppm}$. Potassium ranges between $4.6 \mathrm{ppm}$ and $52.69 \mathrm{ppm}$ across the study area.

The relatively high levels of a number of these parameters during rainy season can be attributed to the presence of decaying organic matter due to use of plant minerals and pesticides in the study area. These values are also indications of polluted water which are capable of increasing the concentrations of hazardous chemical (particularly from intense agrochemical use by farmers) in water in the study area. 


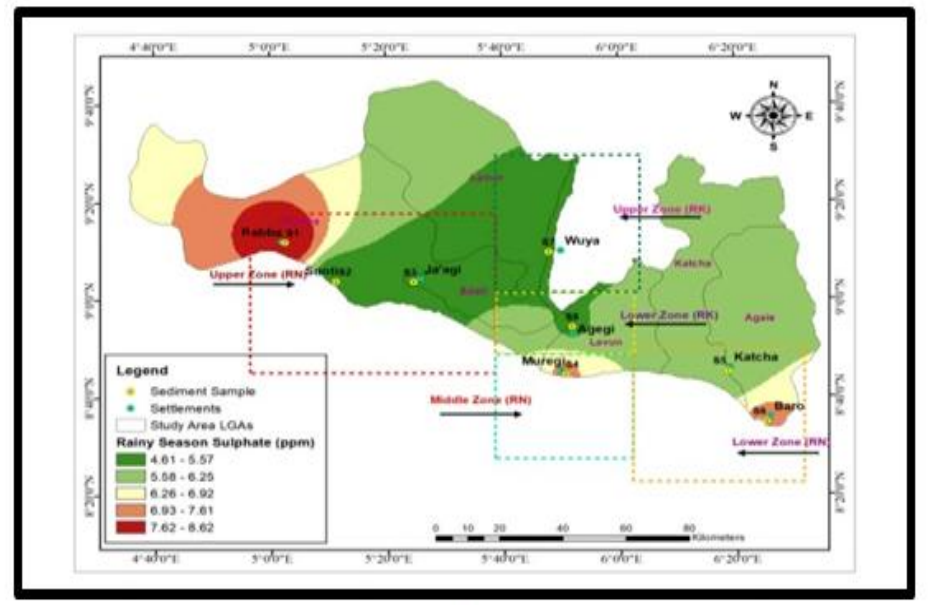

(a)

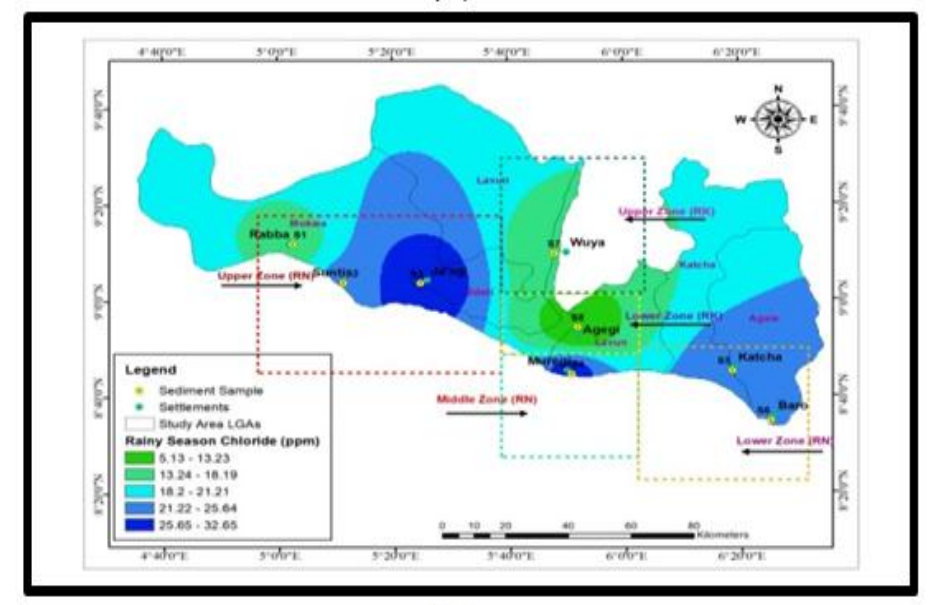

(c)

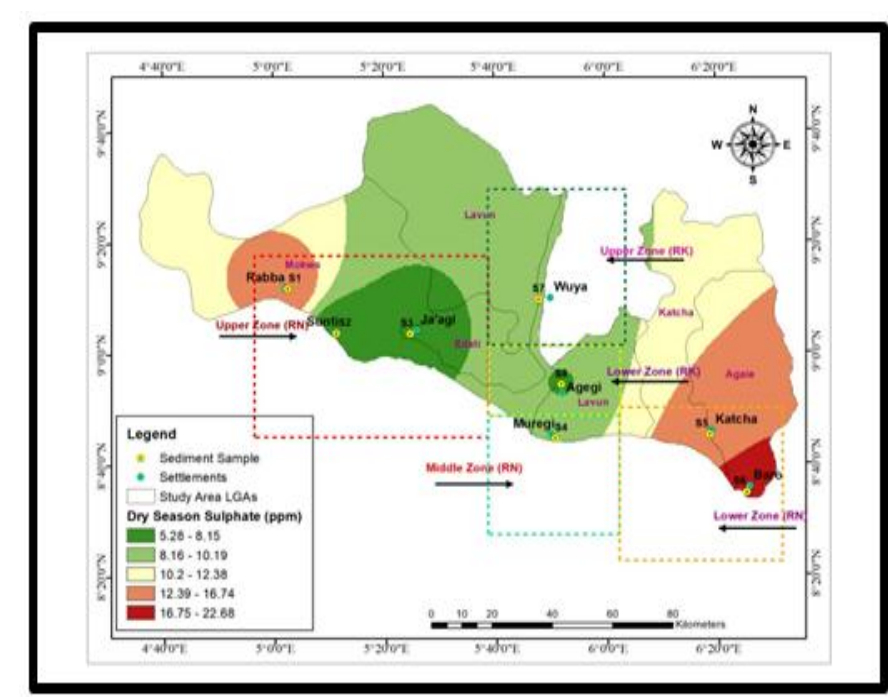

(a)

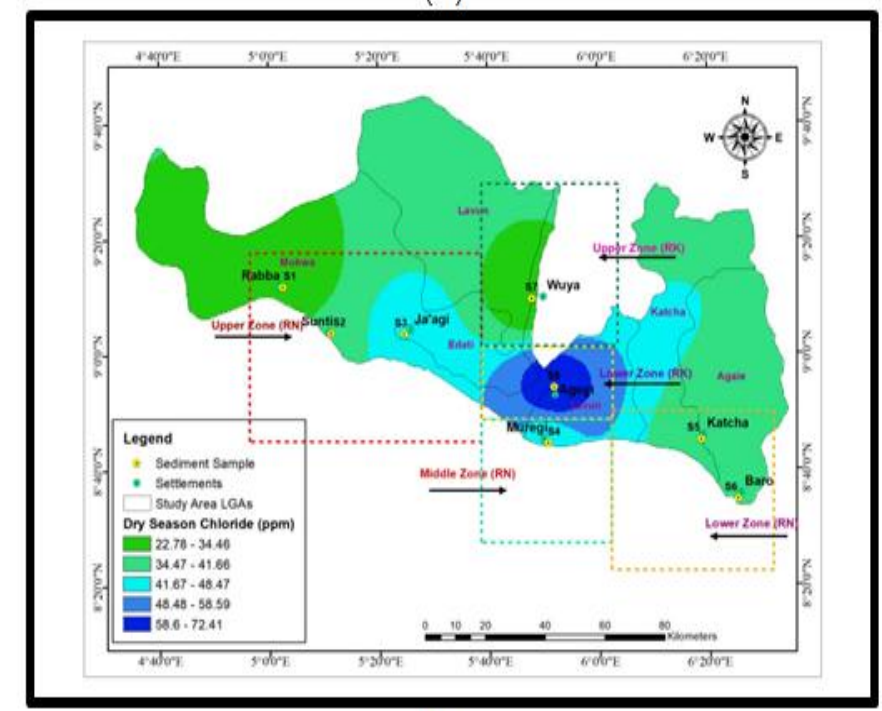

(b)

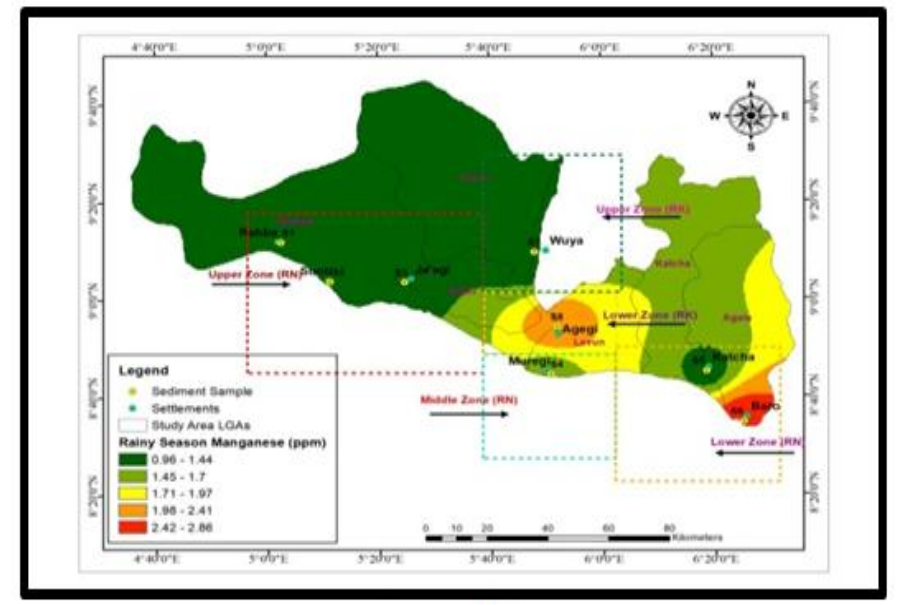

(b)

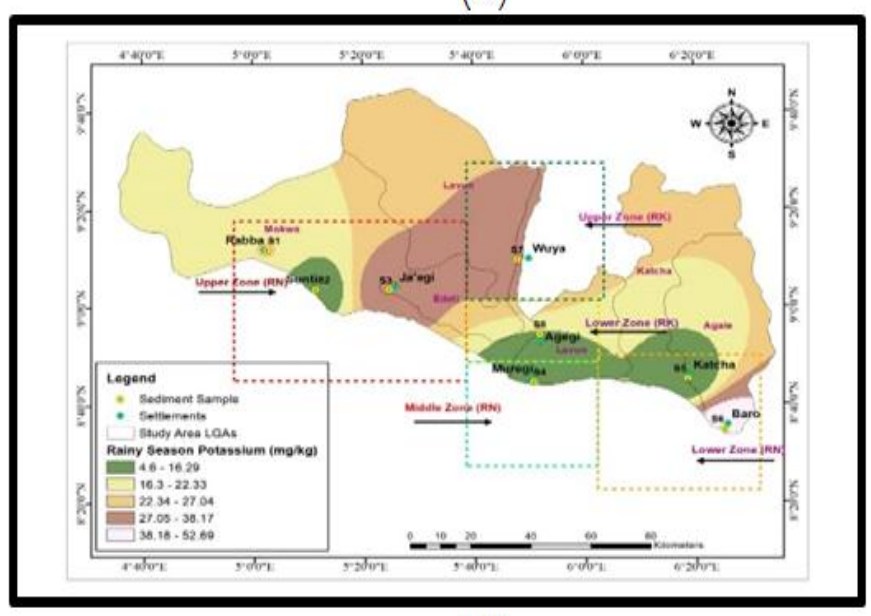

(d)

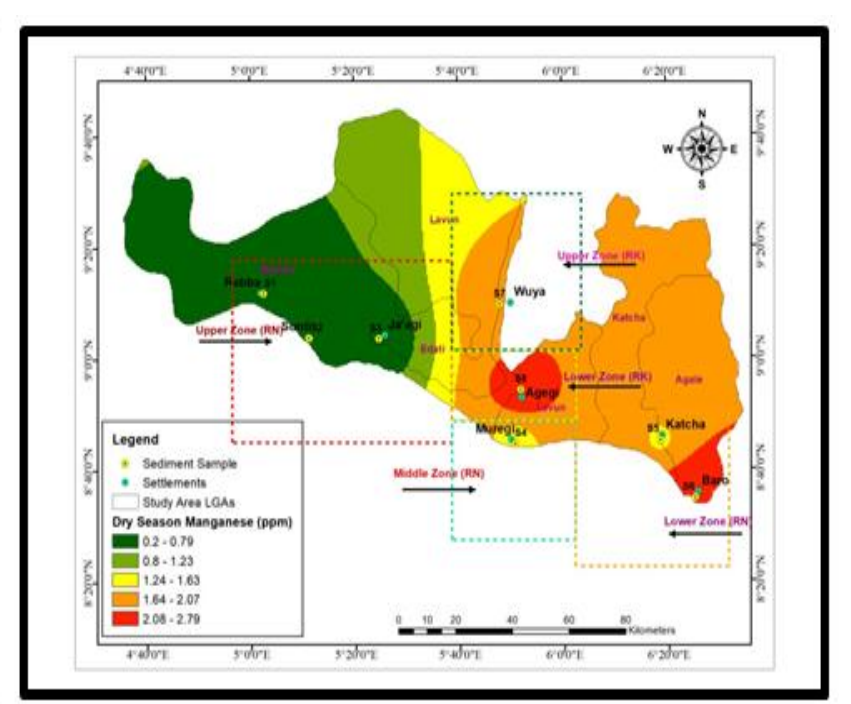

(b)

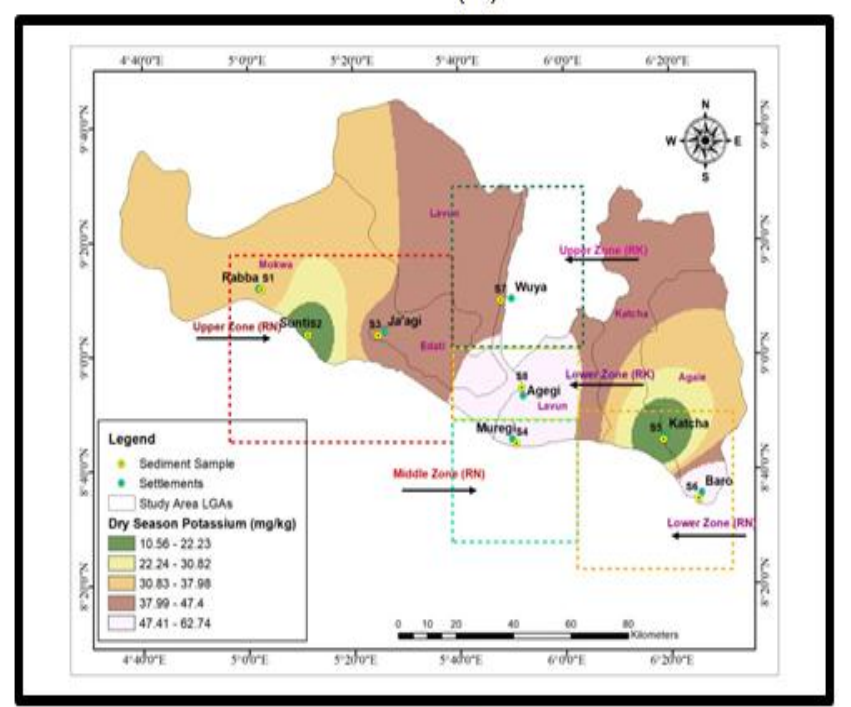

(c)

Figure-6. Interpolated Distance Weighted maps of (a) Sulphate, (b) Mn, (c) Chloride, (d) Potassium of sediment samples of dry season. 


\subsection{Spatial Distribution of Physico-Chemical Characteristics of Sediment Samples during Dry Season}

As revealed in Figure 6 the value of Sulphate concentrations ranges between 5.28ppm and 22.08ppm, Manganese $(\mathrm{Mn})$ ranges between $0.2 \mathrm{ppm}$ and $2.79 \mathrm{ppm}$, Chloride concentrations ranges between 22.78ppm and $72.41 \mathrm{ppm}$. Potassium ranges between $10.56 \mathrm{ppm}$ and $62.74 \mathrm{ppm}$ across the study area.

The relatively high levels of a number of these parameters during dry season can be attributed to the absence of precipitation, presence of decaying organic matter due to use of plant minerals and pesticides in the study area. These values are also indications of polluted water which are capable of increasing the concentrations of hazardous chemical (particularly from intense agrochemical use by farmers) in water in the study area.

\section{Conclusion}

Despite the fact that poor water quality has obviously lead and continue to elicit negative effects on human health and the general environment, little or no attention has been given by related studies to give the problem a befitting spatial coverage. Hence, this study present a comprehensive GIS aided spatial coverage of the physicochemical characteristics of water quality beyond laboratory analytical dimensions. In conclusion, this research has demonstrated the need for effective water quality research tools, government dedication, political wills, and collective responsibility of all stakeholders toward ensuring sustainability of water and it resources in the study area. It is therefore recommended that effective and laudable research tools of this kind be encouraged to guarantee cleaner and healthier water for all.

\section{References}

[1] A. Gogoi, P. Mazumder, V. K. Tyagi, G. T. Chaminda, A. K. An, and M. Kumar, "Occurrence and fate of emerging contaminants in water environment: A review," Groundwater for Sustainable Development, vol. 6, pp. 169-180, 2018.

[2] T. Joko, S. Anggoro, H. R. Sunoko, and S. Rachmawati, Pesticides usage in the soil quality degradation potential in wanasari subdistrict. Brebes. Indonesia: Applied and Environmental Soil Science, 2017.

[3] T. C. Ogwueleka, "Assessment of the water quality and identification of pollution sources of Kaduna River in Niger State (Nigeria) using exploratory data analysis," Water and environment journal, vol. 28, pp. 31-37, 2014.

[4] K. C. Clarke, J. M. Johnson, and T. Trainor, "Contemporary American cartographic research: A review and prospective," Cartography and Geographic Information Science, vol. 46, pp. 196-209, 2019.

[5] A. J. A. IDRIS, T. I. Yahaya, A. S. Abubakar, and A. A. Jigam, "Pesticides and fertilizers use in parts of rivers Niger and Kaduna Catchments, North Central, Nigeria," Asian Review of Environmental and Earth Sciences vol. 7, pp. 18-25, 2020.

[6] W. E. Federation, American public health association. Standard methods for the examination of water and wastewater. Washington, DC, USA: American Public Health Association, 2005. 